\title{
Regularity in Vague Intersection Graphs and Vague Line Graphs
}

\author{
Muhammad Akram, ${ }^{1}$ Wieslaw A. Dudek, ${ }^{2}$ and M. Murtaza Yousaf ${ }^{3}$ \\ ${ }^{1}$ Department of Mathematics, University of the Punjab, New Campus, Lahore, Pakistan \\ ${ }^{2}$ Institute of Mathematics and Computer Science, Wroclaw University of Technology, Wyb. Wyspianskiego 27, \\ 50-370 Wroclaw, Poland \\ ${ }^{3}$ Punjab University College of Information Technology, University of the Punjab, Old Campus, Lahore 54000, Pakistan \\ Correspondence should be addressed to Muhammad Akram; m.akram@pucit.edu.pk
}

Received 3 September 2013; Revised 12 March 2014; Accepted 13 March 2014; Published 15 April 2014

Academic Editor: Fasma Diele

Copyright ( 2014 Muhammad Akram et al. This is an open access article distributed under the Creative Commons Attribution License, which permits unrestricted use, distribution, and reproduction in any medium, provided the original work is properly cited.

Fuzzy graph theory is commonly used in computer science applications, particularly in database theory, data mining, neural networks, expert systems, cluster analysis, control theory, and image capturing. A vague graph is a generalized structure of a fuzzy graph that gives more precision, flexibility, and compatibility to a system when compared with systems that are designed using fuzzy graphs. In this paper, we introduce the notion of vague line graphs, and certain types of vague line graphs and present some of their properties. We also discuss an example application of vague digraphs.

\section{Introduction}

During the last twenty years, line graphs have received considerable attention [1]. A line graph $L\left(G^{*}\right)$ of a graph $G^{*}=(V, E)$, the vertex set of $L\left(G^{*}\right)$ is $E$ and two vertices in $L\left(G^{*}\right)$ are adjacent if and only if their corresponding edges in $G^{*}$ are adjacent. Thus line graphs transform the adjacency relation on edges to an adjacency relation on vertices and thereby provide a mechanism for transferring problems and results on edges to analogous problems and findings about vertices. One of the major results on line graphs is Beineke's [2] characterization of line graphs by a set of nine forbidden induced subgraphs. This approach of finding a forbidden induced subgraph characterization is a popular method of studying the structure of a graph family and has proven to be especially useful for line graphs of various families of graphs.

In 1993, Gau and Buehrer [3] introduced the notion of vague set theory as a generalization of Zadeh's fuzzy set theory. Vague sets are higher order fuzzy sets. Application of higher order fuzzy sets makes the solution procedure more complex, but if the complexity on computation time, computation volume, or memory space is not a matter of concern, then we can achieve better results. In a fuzzy set, each element is associated with a point value selected from the unit interval $[0,1]$, which is termed as the grade of membership in the set. Instead of using point-based membership as in fuzzy sets, interval-based membership is used in a vague set. The interval-based membership in vague sets is more expressive in capturing vagueness of data. There are some interesting features for handling vague data that are unique to vague sets. For example, vague sets allow for a more intuitive graphical representation of vague data, which facilitates significantly better analysis in data relationships, incompleteness, and similarity measures.

In 1975, Rosenfeld [4] first discussed the concept of fuzzy graphs whose basic idea was introduced by Kauffman [5] in 1973. Rosenfeld also proposed the fuzzy relations between fuzzy sets and developed the structure of fuzzy graphs, obtaining analogs of several graph theoretical concepts. Moreover, Bhattacharya [6] gave some remarks on fuzzy graphs and Mordeson [7] introduced the notion of fuzzy line graphs. Bhutani and Battou [8] introduced the concept of $M$-strong fuzzy graphs and described some of their properties. Akram and Dudek [9] discussed some properties of the interval-valued fuzzy graphs. Ramakrishna [10] introduced the concept of vague graphs and studied some of their properties. In this paper, we introduce the notion of vague line graphs and present some of their properties. We 
introduce the concept of certain types of vague line graphs and present some of their properties. We also describe an example application of vague digraphs.

\section{Preliminaries}

By a graph, we mean a pair $G^{*}=(V, E)$, where $V$ is the set and $E$ is a relation on $V$. The elements of $V$ are vertices of $G^{*}$ and the elements of $E$ are edges of $G^{*}$. We write $x y \in E$ to mean $\{x, y\} \in E$, and if $e=x y \in E$, we say $x$ and $y$ are adjacent. Formally, given a graph $G^{*}=(V, E)$, two vertices $x, y \in V$ are said to be neighbors or adjacent nodes if $x y \in E$. The neighbourhood of a vertex $v$ in a graph $G^{*}$ is the induced subgraph of $G^{*}$ consisting of all vertices adjacent to $v$ and all edges connecting two such vertices. The neighbourhood is often denoted by $N(v)$. The degree of vertex $v \operatorname{deg}(v)$ is the number of edges incident on $v$. The set of neighbors, called an open neighborhood $N(v)$ for a vertex $v$ in a graph $G^{*}$, consists of all vertices adjacent to $v$ but not including $v$; that is, $N(v)=\{u \in V \mid v u \in E\}$. When $v$ is also included, it is called a closed neighborhood $N[v]$; that is, $N[v]=N(v) \cup\{v\}$. A regular graph is a graph where each vertex has the same number of neighbors; that is, all the vertices have the same closed neighbourhood degree. An undirected graph $G^{*}$ is connected if there is a path between each pair of distinct vertices. A connected graph is an irregular graph if each of its vertices is adjacent only to vertices with distinct degrees.

An isomorphism of graphs $G_{1}^{*}$ and $G_{2}^{*}$ is a bijection between the vertex sets of $G_{1}^{*}$ and $G_{2}^{*}$ such that any two vertices $v_{1}$ and $v_{2}$ of $G_{1}^{*}$ are adjacent in $G_{1}^{*}$ if and only if $f\left(v_{1}\right)$ and $f\left(v_{2}\right)$ are adjacent in $G_{2}^{*}$. Isomorphic graphs are denoted by $G_{1}^{*} \simeq G_{2}^{*}$.

By an intersection graph of a graph $G^{*}=(V, E)$, we mean a pair $P(S)=(S, T)$, where $S=\left\{S_{1}, S_{2}, \ldots, S_{n}\right\}$ is a family of distinct nonempty subsets of $V$ and $T=\left\{S_{i} S_{j} \mid S_{i}, S_{j} \in\right.$ $\left.S, S_{i} \cap S_{j} \neq \emptyset, i \neq j\right\}$. It is well known that every graph is an intersection graph. By a line graph of a graph $G^{*}=(V, E)$, we mean a pair $L\left(G^{*}\right)=(Z, W)$, where $Z=\left\{\{x\} \cup\left\{u_{x}, v_{x}\right\} \mid x \in\right.$ $\left.E, u_{x}, v_{x} \in V, x=u_{x} v_{x}\right\}$ and $W=\left\{S_{x} S_{y} \mid S_{x} \cap S_{y} \neq \emptyset, x, y \in\right.$ $E, x \neq y\}$ and $S_{x}=\{x\} \cup\left\{u_{x}, v_{x}\right\}, x \in E$. It is reported in the literature that the line graph is an intersection graph.

Proposition 1. If $G^{*}$ is regular of degree $k$, then the line graph $L\left(G^{*}\right)$ is regular of degree $2 k-2$.

Definition 2 (see $[11,12])$. A fuzzy subset $\mu$ on a set $X$ is a map $\mu: X \rightarrow[0,1]$. A fuzzy binary relation on $X$ is a fuzzy subset $\mu$ on $X \times X$. By a fuzzy relation one means a fuzzy binary relation given by $\mu: X \times X \rightarrow[0,1]$.

Definition 3 (see [3]). A vague set $A$ in the universe of discourse $X$ is a pair $\left(t_{A}, f_{A}\right)$, where $t_{A}: X \rightarrow[0,1]$, $f_{A}: X \rightarrow[0,1]$ are true and false membership functions, respectively, such that $t_{A}(x)+f_{A}(x) \leq 1$ for all $x \in X$.

In the above definition, $t_{A}(x)$ is considered as the lower bound for degree of membership of $x$ in $A$ (based on evidence for), and $f_{A}(x)$ is the lower bound for negation of membership of $x$ in $A$ (based on evidence against).
Therefore, the degree of membership of $x$ in the vague set $A$ is characterized by the interval $\left[t_{A}(x), 1-f_{A}(x)\right]$. So, a vague set is a special case of interval-valued sets studied by many mathematicians and applied in many branches of mathematics (see, e.g., $[9,13,14]$ ). Vague sets also have many applications (cf. [15-17]). The interval $\left[t_{A}(x), 1-f_{A}(x)\right]$ is called the vague value of $x$ in $A$ and is denoted by $V_{A}(x)$. We denote zero vague and unit vague value by $\mathbf{0}=[0,0]$ and $\mathbf{1}=[1,1]$, respectively.

It is worth mentioning here that interval-valued fuzzy sets are not vague sets. In interval-valued fuzzy sets, an intervalvalued membership value is assigned to each element of the universe considering the "evidence for $x$ " only, without considering "evidence against $x$." In vague sets both are independently proposed by the decision maker. This makes a major difference in the judgment about the grade of membership.

A vague relation is a further generalization of a fuzzy relation.

Definition 4. Let $X$ and $Y$ be ordinary finite nonempty sets. One can call a vague relation a vague subset of $X \times Y$, that is, an expression $R$ defined by

$$
R=\left\{\left\langle(x, y), t_{R}(x, y), f_{R}(x, y)\right\rangle \mid x \in X, y \in Y\right\},
$$

where $t_{R}: X \times Y \rightarrow[0,1]$ and $f_{R}: X \times Y \rightarrow[0,1]$, which satisfies the condition $0 \leq t_{R}(x, y)+f_{R}(x, y) \leq 1$, for all $(x, y) \in X \times Y$.

\section{Vague Intersection Graphs and Vague Line Graphs}

Throughout this paper, $G^{*}$ will be a crisp graph $(V, E)$ and $G$ a vague graph $(A, B)$ (see Figures 2 and 4$)$. Since an edge $x y \in E$ is identified with an ordered pair $(x, y) \in V \times V$, a vague relation on $E$ can be identified with a vague set on $E$. This gives a possibility to define a vague graph as a pair of vague sets.

Definition 5 (see [10]). A vague relation $B$ on a set $V$ is a vague relation from $V$ to $V$. If $A$ is a vague set on a set $V$, then a vague relation $B$ on $A$ is a vague relation which satisfies

$$
\begin{aligned}
& t_{B}(x y) \leq \min \left(t_{A}(x), t_{A}(y)\right), \\
& f_{B}(x y) \geq \max \left(f_{A}(x), f_{A}(y)\right)
\end{aligned}
$$

for all $x, y \in V$.

Definition 6 (see [10]). Let $V$ be a nonempty set; members of $V$ are called nodes. A vague graph $G=(A, B)$ with $V$ as the set of nodes is a pair of functions $A$ and $B$, where $A$ is a vague set of $V$ and $B$ is a vague relation on $V$.

We note that vague relation $B$ in vague digraph need not be symmetric.

Example 7. Consider a graph $G^{*}=(V, E)$ such that $V=$ $\left\{v_{1}, v_{2}, v_{3}, v_{4}\right\}$ and $E=\left\{v_{1} v_{2}, v_{2} v_{3}, v_{3} v_{4}, v_{4} v_{1}\right\}$. Let $A$ be a vague set on $V$, and let $B$ be a vague relation on $V$ defined by Table 1 . 
TABLE 1

(a)

\begin{tabular}{lcccc}
\hline & $v_{1}$ & $v_{2}$ & $v_{3}$ & $v_{4}$ \\
\hline$t_{A}$ & 0.4 & 0.6 & 0.5 & 0.5 \\
$f_{A}$ & 0.1 & 0.2 & 0.1 & 0.2 \\
\hline
\end{tabular}

(b)

\begin{tabular}{ccccc}
\hline & $v_{1} v_{2}$ & $v_{2} v_{3}$ & $v_{3} v_{4}$ & $v_{4} v_{1}$ \\
\hline$t_{B}$ & 0.1 & 0.2 & 0.3 & 0.4 \\
$f_{B}$ & 0.6 & 0.7 & 0.6 & 0.6 \\
\hline
\end{tabular}

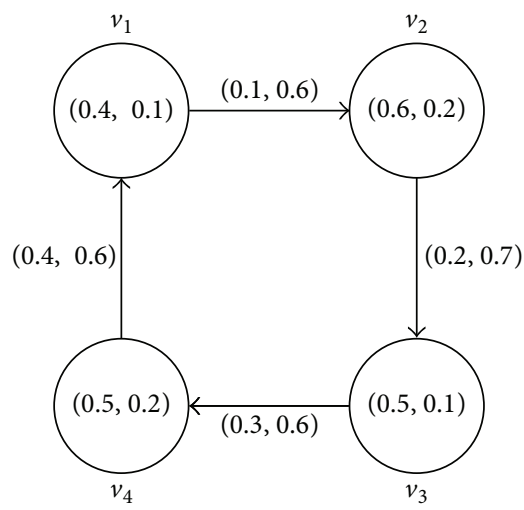

FIGURE 1: Vague digraph.

By routine computations, it is easy to see from Figure 1 that $G=(A, B)$ is a vague digraph.

Definition 8. Consider an intersection graph $P(S)=(S, T)$ of a crisp graph $G^{*}=(V, E)$. Let $A_{1}=\left(t_{A_{1}}, f_{A_{1}}\right)$ and $B_{1}=\left(t_{B_{1}}, f_{B_{1}}\right)$ be vague sets on $V$ and $E$ and $A_{2}=\left(t_{A_{2}}, f_{A_{2}}\right)$ and $B_{2}=\left(t_{B_{2}}, f_{B_{2}}\right)$ on $S$ and $T$, respectively. Then a vague intersection graph of the vague graph $G=\left(A_{1}, B_{1}\right)$ is a vague graph $P(G)=\left(A_{2}, B_{2}\right)$ such that

(a) $t_{A_{2}}\left(S_{i}\right)=t_{A_{1}}\left(v_{i}\right), f_{A_{2}}\left(S_{i}\right)=f_{A_{1}}\left(v_{i}\right)$,

(b) $t_{B_{2}}\left(S_{i} S_{j}\right)=t_{B_{1}}\left(v_{i} v_{j}\right), f_{B_{2}}\left(S_{i} S_{j}\right)=f_{B_{1}}\left(v_{i} v_{j}\right)$

for all $S_{i}, S_{j} \in S, S_{i} S_{j} \in T$.

Example 9. Consider a graph $G^{*}=(V, E)$, where $V=$ $\left\{v_{1}, v_{2}, v_{3}\right\}$ is the set of vertices and $E=\left\{v_{1} v_{2}, v_{2} v_{3}, v_{3} v_{1}\right\}$ is the set of edges. Consider $G=\left(A_{1}, B_{1}\right)$, where $A_{1}$ and $B_{1}$ are vague set and vague relation on $V$, respectively. We define Table 2.

By routine computations, it is easy to see from Figure 3 that $G$ is a vague graph. Consider an intersection graph $P(S)=$ $(S, T)$ such that

$$
\begin{gathered}
S=\left\{S_{1}=\left\{v_{1}, v_{2}\right\}, S_{2}=\left\{v_{2}, v_{3}\right\}, S_{3}=\left\{v_{1}, v_{3}\right\}\right\}, \\
T=\left\{S_{1} S_{2}, S_{2} S_{3}, S_{3} S_{1}\right\} .
\end{gathered}
$$

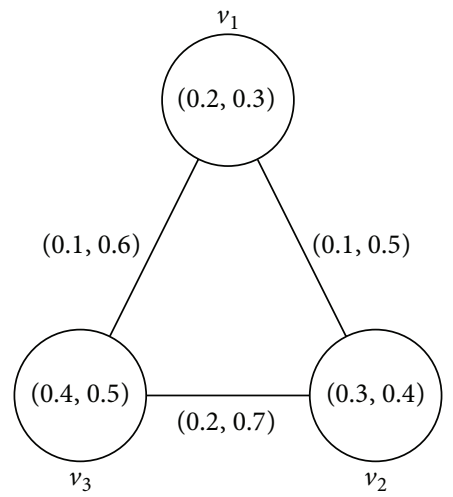

Figure 2: Vague graph.

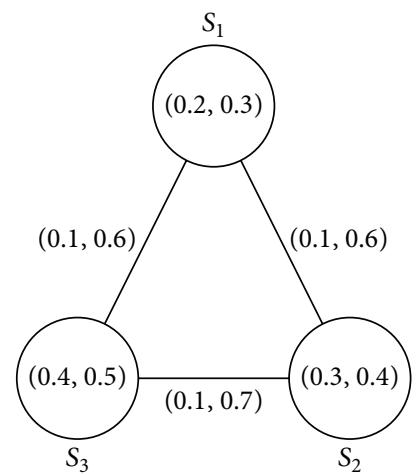

Figure 3: Vague intersection graph.

Let $A_{2}=\left(t_{A_{2}}, f_{A_{2}}\right)$ and $B_{2}=\left(t_{B_{2}}, f_{B_{2}}\right)$ be vague sets on $S$ and $T$, respectively. Then, by routine computations, we have

$$
\begin{gathered}
t_{A_{2}}\left(S_{1}\right)=t_{A_{1}}\left(v_{1}\right)=0.2, \\
t_{A_{2}}\left(S_{2}\right)=t_{A_{1}}\left(v_{2}\right)=0.3, \\
t_{A_{2}}\left(S_{3}\right)=t_{A_{1}}\left(v_{3}\right)=0.4, \\
f_{A_{2}}\left(S_{1}\right)=f_{A_{1}}\left(v_{1}\right)=0.3, \\
f_{A_{2}}\left(S_{2}\right)=f_{A_{1}}\left(v_{2}\right)=0.4, \\
f_{A_{2}}\left(S_{3}\right)=f_{A_{1}}\left(v_{3}\right)=0.5, \\
t_{B_{2}}\left(S_{1} S_{2}\right)=t_{B_{1}}\left(v_{1} v_{2}\right)=0.1, \\
t_{B_{2}}\left(S_{2} S_{3}\right)=t_{B_{1}}\left(v_{2} v_{3}\right)=0.1, \\
t_{B_{2}}\left(S_{3} S_{1}\right)=t_{B_{1}}\left(v_{3} v_{1}\right)=0.1, \\
f_{B_{2}}\left(S_{1} S_{2}\right)=f_{B_{1}}\left(v_{1} v_{2}\right)=0.6, \\
f_{B_{2}}\left(S_{2} S_{3}\right)=f_{B_{1}}\left(v_{2} v_{3}\right)=0.7, \\
f_{B_{2}}\left(S_{3} S_{1}\right)=f_{B_{1}}\left(v_{3} v_{1}\right)=0.6 .
\end{gathered}
$$

By routine computations, it is easy to see that $P(G)$ is a vague intersection graph. 
TABLE 2

(a)

\begin{tabular}{lccc}
\hline & $v_{1}$ & $v_{2}$ & $v_{3}$ \\
\hline$t_{A_{1}}$ & 0.2 & 0.3 & 0.4 \\
$f_{A_{1}}$ & 0.3 & 0.4 & 0.5 \\
\hline
\end{tabular}

(b)

\begin{tabular}{lccc}
\hline & $v_{1} v_{2}$ & $v_{2} v_{3}$ & $v_{3} v_{1}$ \\
\hline$t_{B_{1}}$ & 0.1 & 0.2 & 0.1 \\
$f_{B_{1}}$ & 0.5 & 0.7 & 0.6 \\
\hline
\end{tabular}

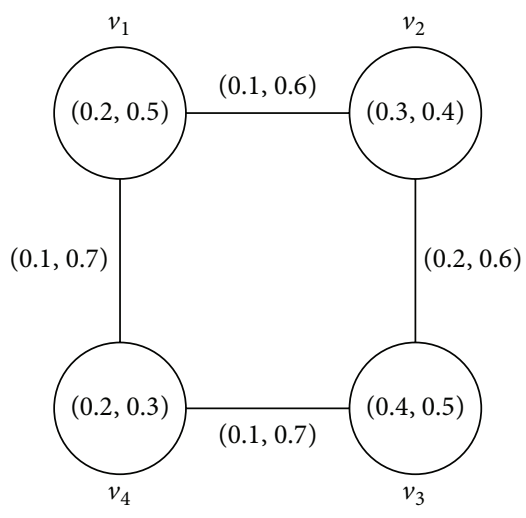

Figure 4: Vague graph.

Proposition 10. Let $G=\left(A_{1}, B_{1}\right)$ be a vague graph of $G^{*}$ and let $P(G)=\left(A_{2}, B_{2}\right)$ be a vague intersection graph of $P(S)$. Then

(a) a vague intersection graph is a vague graph;

(b) a vague graph is isomorphic to a vague intersection graph.

Proof. (a) From Definition 6, it follows that

$$
\begin{gathered}
t_{B_{2}}\left(S_{i} S_{j}\right)=t_{B_{1}}\left(v_{i} v_{j}\right) \leq \min \left(t_{A_{1}}\left(v_{i}\right), t_{A_{1}}\left(v_{j}\right)\right), \\
f_{B_{2}}\left(S_{i} S_{j}\right)=f_{B_{1}}\left(v_{i} v_{j}\right) \geq \max \left(f_{A_{1}}\left(v_{i}\right), f_{A_{1}}\left(v_{j}\right)\right) .
\end{gathered}
$$

This shows that a vague intersection graph is a vague graph.

(b) Define $\varphi: V \rightarrow S$ by $\varphi\left(v_{i}\right)=s_{i}$, for $i=1,2 \ldots, n$. Clearly, $\varphi$ is a one-to-one function of $V$ onto $S$. Now $v_{i} v_{j} \in E$ if and only if $s_{i} s_{j} \in T$ and $T=\left\{\varphi\left(v_{i}\right) \varphi\left(v_{j}\right) \mid v_{i} v_{j} \in E\right\}$. Also

$$
\begin{gathered}
t_{A_{2}}\left(\varphi\left(v_{i}\right)\right)=t_{A_{2}}\left(S_{i}\right)=t_{A_{1}}\left(v_{i}\right), \\
f_{A_{2}}\left(\varphi\left(v_{i}\right)\right)=f_{A_{2}}\left(S_{i}\right)=f_{A_{1}}\left(v_{i}\right), \\
t_{B_{2}}\left(\varphi\left(v_{i}\right) \varphi\left(v_{j}\right)\right)=t_{B_{2}}\left(S_{i} S_{j}\right)=t_{B_{1}}\left(v_{i} v_{j}\right), \\
f_{B_{2}}\left(\varphi\left(v_{i}\right) \varphi\left(v_{j}\right)\right)=f_{B_{2}}\left(S_{i} S_{j}\right)=f_{B_{1}}\left(v_{i} v_{j}\right) .
\end{gathered}
$$

Thus $\varphi$ is an isomorphism of $G$ onto $P(G)$.

Definition 11. Let $L\left(G^{*}\right)=(Z, W)$ be a line graph of a crisp graph $G^{*}=(V, E)$. Let $A_{1}=\left(t_{A_{1}}, f_{A_{1}}\right)$ and $B_{1}=\left(t_{B_{1}}, f_{B_{1}}\right)$ be
TABLE 3

(a)

\begin{tabular}{lcccc}
\hline & $v_{1}$ & $v_{2}$ & $v_{3}$ & $v_{4}$ \\
\hline$t_{A_{1}}$ & 0.2 & 0.3 & 0.4 & 0.2 \\
$f_{A_{1}}$ & 0.5 & 0.4 & 0.5 & 0.3 \\
\hline
\end{tabular}

(b)

\begin{tabular}{lllll}
\hline & $x_{1}$ & $x_{2}$ & $x_{3}$ & $x_{4}$ \\
\hline$t_{B_{1}}$ & 0.1 & 0.2 & 0.1 & 0.1 \\
$f_{B_{1}}$ & 0.6 & 0.6 & 0.7 & 0.7 \\
\hline
\end{tabular}

vague sets on $V$ and $E$ and $A_{2}=\left(t_{A_{2}}, f_{A_{2}}\right)$ and $B_{2}=\left(t_{B_{2}}, f_{B_{2}}\right)$ on $Z$ and $W$, respectively. Then a vague line graph of the vague graph $G=\left(A_{1}, B_{1}\right)$ is a vague graph $L(G)=\left(A_{2}, B_{2}\right)$ such that

(i) $t_{A_{2}}\left(S_{x}\right)=t_{B_{1}}(x)=t_{B_{1}}\left(u_{x} v_{x}\right)$,

(ii) $f_{A_{2}}\left(S_{x}\right)=f_{B_{1}}(x)=f_{B_{1}}\left(u_{x} v_{x}\right)$,

(iii) $t_{B_{2}}\left(S_{x} S_{y}\right)=\min \left(t_{B_{1}}(x), t_{B_{1}}(y)\right)$,

(iv) $f_{B_{2}}\left(S_{x} S_{y}\right)=\max \left(f_{B_{1}}(x), f_{B_{1}}(y)\right)$

for all $S_{x}, S_{y} \in Z, S_{x} S_{y} \in W$.

Example 12. Consider a crisp graph $G^{*}=(V, E)$, where $V=$ $\left\{v_{1}, v_{2}, v_{3}, v_{4}\right\}$ is the set of vertices, and $E=\left\{x_{1}=v_{1} v_{2}, x_{2}=\right.$ $\left.v_{2} v_{3}, x_{3}=v_{3} v_{4}, x_{4}=v_{4} v_{1}\right\}$ is the set of edges. Let $A_{1}$ be a vague set on $V$ and let $B_{1}$ be vague relation on $V$ defined by Table 3.

By routine computations, it is easy to see that $G=\left(A_{1}, B_{1}\right)$ is a vague graph. Consider a line graph $L\left(G^{*}\right)=(Z, W)$ such that

$$
\begin{gathered}
Z=\left\{S_{x_{1}}, S_{x_{2}}, S_{x_{3}}, S_{x_{4}}\right\}, \\
W=\left\{S_{x_{1}} S_{x_{2}}, S_{x_{2}} S_{x_{3}}, S_{x_{3}} S_{x_{4}}, S_{x_{4}} S_{x_{1}}\right\} .
\end{gathered}
$$

Let $A_{2}=\left(t_{A_{2}}, f_{A_{2}}\right)$ and $B_{2}=\left(t_{B_{2}}, f_{B_{2}}\right)$ be vague sets on $Z$ and $W$, respectively. Then, by routine computations, we have

$$
\begin{array}{ll}
t_{A_{2}}\left(S_{x_{1}}\right)=0.1, & t_{A_{2}}\left(S_{x_{2}}\right)=0.2, \\
t_{A_{2}}\left(S_{x_{3}}\right)=0.1, & t_{A_{2}}\left(S_{x_{4}}\right)=0.1, \\
f_{A_{2}}\left(S_{x_{1}}\right)=0.6, & f_{A_{2}}\left(S_{x_{2}}\right)=0.6, \\
f_{A_{2}}\left(S_{x_{3}}\right)=0.7, & f_{A_{2}}\left(S_{x_{4}}\right)=0.7, \\
t_{B_{2}}\left(S_{x_{1}} S_{x_{2}}\right)=0.1, & t_{B_{2}}\left(S_{x_{2}} S_{x_{3}}\right)=0.1, \\
t_{B_{2}}\left(S_{x_{3}} S_{x_{4}}\right)=0.1, & t_{B_{2}}\left(S_{x_{4}} S_{x_{1}}\right)=0.1, \\
f_{B_{2}}\left(S_{x_{1}} S_{x_{2}}\right)=0.6, & f_{B_{2}}\left(S_{x_{2}} S_{x_{3}}\right)=0.7, \\
f_{B_{2}}\left(S_{x_{3}} S_{x_{4}}\right)=0.7, & f_{B_{2}}\left(S_{x_{4}} S_{x_{1}}\right)=0.7 .
\end{array}
$$

By routine computations, it is clear that $L(G)=\left(A_{2}, B_{2}\right)$ is a vague line graph (see Figure 5). 


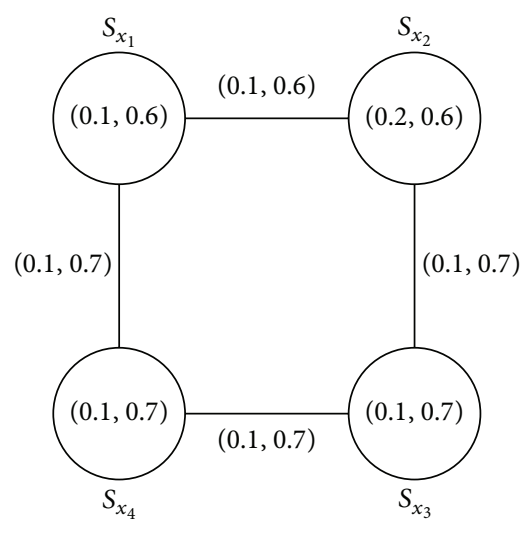

FigURE 5: Vague line graph.

Remark 13. $L(G)=\left(A_{2}, B_{2}\right)$ is a vague line graph corresponding to the vague graph $G=\left(A_{1}, B_{1}\right)$.

Proposition 14. If $L(G)=\left(A_{2}, B_{2}\right)$ is a vague line graph of a vague graph $G=\left(A_{1}, B_{1}\right)$, then $L\left(G^{*}\right)=(Z, W)$ is the line graph of $G^{*}=(V, E)$.

Proposition 15. $L(G)=\left(A_{2}, B_{2}\right)$ is a vague line graph of some vague graph $G=\left(A_{1}, B_{1}\right)$ if and only if

$$
\begin{aligned}
& t_{B_{2}}\left(S_{x} S_{y}\right)=\min \left(t_{A_{2}}\left(S_{x}\right), t_{A_{2}}\left(S_{y}\right)\right), \\
& f_{B_{2}}\left(S_{x} S_{y}\right)=\max \left(f_{A_{2}}\left(S_{x}\right), f_{A_{2}}\left(S_{y}\right)\right)
\end{aligned}
$$

for all $S_{x}, S_{y} \in W$.

Proof. Assume that $t_{B_{2}}\left(S_{x} S_{y}\right)=\min \left(t_{A_{2}}\left(S_{x}\right), t_{A_{2}}\left(S_{y}\right)\right)$ for all $S_{x}, S_{y} \in W$. We define $t_{A_{1}}(x)=t_{A_{2}}\left(S_{x}\right)$ for all $x \in E$. Then

$$
\begin{aligned}
t_{B_{2}}\left(S_{x} S_{y}\right) & =\min \left(t_{A_{2}}\left(S_{x}\right), t_{A_{2}}\left(S_{y}\right)\right) \\
& =\min \left(t_{A_{1}}(x), t_{A_{1}}(y)\right), \\
f_{B_{2}}\left(S_{x} S_{y}\right) & =\max \left(f_{A_{2}}\left(S_{x}\right), f_{A_{2}}\left(S_{y}\right)\right) \\
& =\max \left(f_{A_{1}}(x), f_{A_{1}}(y)\right) .
\end{aligned}
$$

A vague set $A_{1}=\left(t_{A_{1}}, f_{A_{1}}\right)$ that yields the properties

$$
\begin{aligned}
& t_{B_{1}}(x y) \leq \min \left(t_{A_{1}}(x), t_{A_{1}}(y)\right) \\
& f_{B_{1}}(x y) \geq \max \left(f_{A_{1}}(x), f_{A_{1}}(y)\right)
\end{aligned}
$$

will suffice.

The converse part is obvious.

Another characterization of vague line graphs of vague graphs is given by the following proposition.
Proposition 16. $L(G)=\left(A_{2}, B_{2}\right)$ is a vague line graph of some vague graph if and only if $L\left(G^{*}\right)=(Z, W)$ is a line graph such that

$$
\begin{aligned}
& t_{B_{2}}(u v)=\min \left(t_{A_{2}}(u), t_{A_{2}}(v)\right), \\
& f_{B_{2}}(u v)=\max \left(f_{A_{2}}(u), f_{A_{2}}(v)\right)
\end{aligned}
$$

for all $u v \in W$.

Definition 17. Let $G_{1}=\left(A_{1}, B_{1}\right)$ and $G_{2}=\left(A_{2}, B_{2}\right)$ be two vague graphs. A homomorphism $\varphi: G_{1} \rightarrow G_{2}$ is a mapping $\varphi: V_{1} \rightarrow V_{2}$ such that

(a) $t_{A_{1}}\left(x_{1}\right) \leq t_{A_{2}}\left(\varphi\left(x_{1}\right)\right), f_{A_{1}}\left(x_{1}\right) \geq f_{A_{2}}\left(\varphi\left(x_{1}\right)\right)$,

(b) $t_{B_{1}}\left(x_{1} y_{1}\right) \leq t_{B_{2}}\left(\varphi\left(x_{1}\right) \varphi\left(y_{1}\right)\right), f_{B_{1}}\left(x_{1} y_{1}\right) \quad \geq$ $f_{B_{2}}\left(\varphi\left(x_{1}\right) \varphi\left(y_{1}\right)\right)$

for all $x_{1} \in V_{1}, x_{1} y_{1} \in E_{1}$, and $\varphi\left(x_{1} y_{1}\right) \in E_{2}$.

A bijective homomorphism $\varphi: G_{1} \rightarrow G_{2}$ of vague graphs is called a weak vertex-isomorphism if

(c) $t_{A_{1}}\left(x_{1}\right)=t_{A_{2}}\left(\varphi\left(x_{1}\right)\right), f_{A_{1}}\left(x_{1}\right)=f_{A_{2}}\left(\varphi\left(x_{1}\right)\right)$,

for all $x_{1} \in V_{1}$, and a weak line-isomorphism if

(d) $t_{B_{1}}\left(x_{1} y_{1}\right)=t_{B_{2}}\left(\varphi\left(x_{1}\right) \varphi\left(y_{1}\right)\right), f_{B_{1}}\left(x_{1} y_{1}\right)=$ $f_{B_{2}}\left(\varphi\left(x_{1}\right) \varphi\left(y_{1}\right)\right)$,

for all $x_{1} y_{1} \in E_{1}$. A bijective homomorphism $\varphi: G_{1} \rightarrow G_{2}$ satisfying $(c)$ and $(d)$ is called a weak isomorphism of vague graphs $G_{1}$ and $G_{2}$. A weak isomorphism preserves the weights of the vertices but not necessarily the weights of the edges.

The following fact is obvious.

Proposition 18. A weak isomorphism of vague graphs $G_{1}$ and $G_{2}$ is an isomorphism of their crisp graphs $G_{1}^{*}$ and $G_{2}^{*}$.

Theorem 19. Let $L(G)=\left(A_{2}, B_{2}\right)$ be the vague line graph corresponding to the vague graph $G=\left(A_{1}, B_{1}\right)$. Suppose that $G^{*}=(V, E)$ is connected. Then one has the following.

(i) There exists a weak isomorphism of $G$ onto $L(G)$ if and only if $G^{*}$ is a cycle and for all $v \in V, x \in E, t_{A_{1}}(v)=$ $t_{B_{1}}(x), f_{A_{1}}(v)=f_{B_{1}}(x)$; that is, $A_{1}=\left(t_{A_{1}}, f_{A_{1}}\right)$ and $B_{1}=\left(t_{B_{1}}, f_{B_{1}}\right)$ are constant functions on $V$ and $E$, respectively, taking on the same value.

(ii) If $\varphi$ is a weak isomorphism of $G$ onto $L(G)$, then $\varphi$ is an isomorphism.

Proof. Assume that $\varphi$ is a weak isomorphism of $G$ onto $L(G)$. From Proposition 15, it follows that $G^{*}=(V, E)$ is a cycle [18, Theorem 8.2, page 72]. Let $V=\left\{v_{1}, v_{2}, \ldots, v_{n}\right\}$ and $E=\left\{x_{1}=\right.$ $\left.v_{1} v_{2}, x_{2}=v_{2} v_{3}, \ldots, x_{n}=v_{n} v_{1}\right\}$, where $v_{1} v_{2} v_{3}, \ldots, v_{n}$ is a cycle. Define vague sets

$$
\begin{array}{cl}
t_{A_{1}}\left(v_{i}\right)=s_{i}, \quad & f_{A_{1}}\left(v_{i}\right)=s_{i}^{\prime}, \\
t_{B_{1}}\left(x_{i}\right)=t_{B_{1}}\left(v_{i} v_{i+1}\right)=r_{i}, \quad & f_{B_{1}}\left(x_{i}\right)=f_{B_{1}}\left(v_{i} v_{i+1}\right)=r_{i}^{\prime}, \\
i & i=1,2, \ldots, n, v_{n+1}=v_{1} .
\end{array}
$$


Then for $s_{n+1}=s_{1}$ and $s_{n+1}^{\prime}=s_{1}^{\prime}$, we have

$$
\begin{array}{r}
r_{i} \leq \min \left(s_{i}, s_{i+1}\right), \quad r_{i}^{\prime} \geq \max \left(s_{i}^{\prime}, s_{i+1}^{\prime}\right), \\
i=1,2, \ldots, n .
\end{array}
$$

Now

$$
\begin{aligned}
& Z=\left\{S_{x_{1}}, S_{x_{2}}, S_{x_{3}}, \ldots, S_{x_{n}}\right\}, \\
& W=\left\{S_{x_{1}} S_{x_{2}}, S_{x_{2}} S_{x_{3}}, \ldots, S_{x_{n}} S_{x_{1}}\right\} .
\end{aligned}
$$

Thus for $r_{n+1}=r_{1}$, we obtain

$$
\begin{aligned}
& t_{A_{2}}\left(S_{x_{i}}\right)=t_{B_{1}}\left(x_{i}\right)=r_{i}, \quad f_{A_{2}}\left(S_{x_{i}}\right)=f_{B_{1}}\left(x_{i}\right)=r_{i}^{\prime}, \\
& t_{B_{2}}\left(S_{x_{i}} S_{x_{i+1}}\right)=\min \left(t_{B_{1}}\left(x_{i}\right), t_{B_{1}}\left(x_{i+1}\right)\right)=\min \left(r_{i}, r_{i+1}\right), \\
& f_{B_{2}}\left(S_{x_{i}} S_{x_{i+1}}\right)=\max \left(f_{B_{1}}\left(x_{i}\right), f_{B_{1}}\left(x_{i+1}\right)\right)=\max \left(r_{i}^{\prime}, r_{i+1}^{\prime}\right)
\end{aligned}
$$

for $i=1,2, \ldots, n, v_{n+1}=v_{1}$. Since $\varphi$ is an isomorphism of $G^{*}$ onto $L\left(G^{*}\right), \varphi$ is a bijective map of $V$ onto $Z$. Also $\varphi$ preserves adjacency. Hence $\varphi$ induces a permutation $\pi$ of $\{1,2, \ldots, n\}$ such that

$$
\begin{gathered}
\varphi\left(v_{i}\right)=S_{v_{\pi(i)} v_{\pi(i)+1}}, \\
v_{i} v_{i+1} \longrightarrow \varphi\left(v_{i}\right) \varphi\left(v_{i+1}\right)=S_{v_{\pi(i)} v_{\pi(i)+1}} S_{v_{\pi(i+1)} v_{\pi(i+1)+1}}, \\
\quad i=1,2, \ldots, n-1 .
\end{gathered}
$$

Thus

$$
\begin{aligned}
s_{i} & =t_{A_{1}}\left(v_{i}\right) \leq t_{A_{2}}\left(\varphi\left(v_{i}\right)\right) \\
& =t_{A_{2}}\left(S_{v_{\pi(i)} v_{\pi(i)+1}}\right) \\
& =t_{B_{1}}\left(v_{\pi(i)} v_{\pi(i)+1}\right)=r_{\pi(i)}, \\
s_{i}^{\prime} & =f_{A_{1}}\left(v_{i}\right) \geq f_{A_{2}}\left(\varphi\left(v_{i}\right)\right)=f_{A_{2}}\left(S_{v_{\pi(i)} v_{\pi(i)+1}}\right) \\
& =f_{B_{1}}\left(v_{\pi(i)} v_{\pi(i)+1}\right)=r_{\pi(i)}^{\prime}, \\
r_{i} & =t_{B_{1}}\left(v_{i} v_{i+1}\right) \leq t_{B_{2}}\left(\varphi\left(v_{i}\right) \varphi\left(v_{i+1}\right)\right) \\
& =t_{B_{2}}\left(S_{v_{\pi(i)} v_{\pi(i)+1}} S_{v_{\pi(i+1)} v_{\pi(i+1)+1}}\right) \\
& =\min \left(t_{B_{1}}\left(v_{\pi(i)} v_{\pi(i)+1}\right), t_{B_{1}}\left(v_{\pi(i+1)} v_{\pi(i+1)+1}\right)\right) \\
& =\min \left(r_{\pi(i)}, r_{\pi(i+1)}\right) .
\end{aligned}
$$

Similarly,

$$
\begin{aligned}
r_{i}^{\prime} & =f_{B_{1}}\left(v_{i} v_{i+1}\right) \\
& \geq f_{B_{2}}\left(\varphi\left(v_{i}\right) \varphi\left(v_{i+1}\right)\right) \\
& =f_{B_{2}}\left(S_{v_{\pi(i)} v_{\pi(i)+1}} S_{v_{\pi(i+1)} v_{\pi(i+1)+1}}\right) \\
& =\max \left(f_{B_{1}}\left(v_{\pi(i)} v_{\pi(i)+1}\right), f_{B_{1}}\left(v_{\pi(i+1)} v_{\pi(i+1)+1}\right)\right) \\
& =\max \left(r_{\pi(i)}^{\prime}, r_{\pi(i+1)}^{\prime}\right)
\end{aligned}
$$

for $i=1,2, \ldots, n$. That is,

$$
\begin{gathered}
s_{i} \leq r_{\pi(i)}, \quad s_{i}^{\prime} \geq r_{\pi}^{\prime}(i), \\
r_{i} \leq \min \left(r_{\pi(i)}, r_{\pi(i+1)}\right), \quad r_{i}^{\prime} \geq \max \left(r_{\pi(i)}^{\prime}, r_{\pi(i+1)}^{\prime}\right) .
\end{gathered}
$$

Thus, $r_{i} \leq r_{\pi(i)}$ and $r_{i}^{\prime} \geq r_{\pi(i)}^{\prime}$ and so $r_{\pi(i)} \leq r_{\pi(\pi(i))}$ and $r_{\pi(i)}^{\prime} \geq r_{\pi(\pi(i))}^{\prime}$ for all $i=1,2, \ldots, n$. Continuing, we obtain

$$
\begin{aligned}
& r_{i} \leq r_{\pi(i)} \leq \cdots \leq r_{\pi^{j}(i)} \leq r_{i} \\
& r_{i}^{\prime} \geq r_{\pi(i)}^{\prime} \geq \cdots \geq r_{\pi^{j}(i)}^{\prime} \geq r_{i}^{\prime},
\end{aligned}
$$

where $\pi^{j+1}$ is the identity map. So, $r_{i}=r_{\pi(i)}$ and $r_{i}^{\prime}=r_{\pi(i)}^{\prime}$ for all $i=1,2, \ldots, n$. But, by (21), we also have $r_{i} \leq r_{\pi(i+1)}=r_{i+1}$ and $r_{i}^{\prime} \geq r_{\pi(i+1)}^{\prime}=r_{i+1}^{\prime}$, which together with $r_{n+1}=r_{1}$ and $r_{n+1}^{\prime}=r_{1}^{\prime}$ imply $r_{i}=r_{1}$ and $r_{i}^{\prime}=r_{1}^{\prime}$ for all $i=1,2, \ldots, n$. Hence by (14) and (20), we get

$$
\begin{aligned}
& r_{1}=\cdots=r_{n}=s_{1}=\cdots=s_{n}, \\
& r_{1}^{\prime}=\cdots=r_{n}^{\prime}=s_{1}^{\prime}=\cdots=s_{n}^{\prime} .
\end{aligned}
$$

Thus we have not only proven the conclusion about $A_{1}$ and $B_{1}$ being constant function, but also shown that (ii) holds.

The converse part of (i) is obvious.

We state the following theorem without proof.

Theorem 20. Let $G$ and $H$ be vague graphs of $G^{*}$ and $H^{*}$, respectively, such that $G^{*}$ and $H^{*}$ are connected. Let $L\left(G^{*}\right)$ and $L\left(H^{*}\right)$ be the line graphs corresponding to $G$ and $H$, respectively. Suppose that it is not the case that one of $G^{*}$ and $H^{*}$ is complete graph $K_{3}$ and the other is bipartite complete graph $K_{1,3}$. If $L(G)$ and $L\left(H^{*}\right)$ are isomorphic, then $G$ and $H$ are line-isomorphic.

\section{Regular Vague Intersection Graphs and Vague Line Graphs}

Definition 21. A vague graph $G$ is called complete if

$$
\begin{aligned}
& t_{B}(x y)=\min \left(t_{A}(x), t_{A}(y)\right), \\
& f_{B}(x y)=\max \left(f_{A}(x), f_{A}(y)\right)
\end{aligned}
$$

for each edge $x y \in E$.

Example 22. Consider a vague graph $G$.

Routine computations show that $G$ is complete (see Figure 6).

Definition 23. Let $G$ be a vague graph on $G^{*}$. If all the vertices have the same open neighbourhood degree $m$, then $G$ is called a regular vague graph. The neighbourhood degree of a vertex $x$ in $G$ is defined by $\operatorname{deg}(x)=\left(\operatorname{deg}_{t}(x), \operatorname{deg}_{f}(x)\right)$, where $\operatorname{deg}_{t}(x)=\sum_{y \in N(x)} t_{A}(y)$ and $\operatorname{deg}_{f}(x)=\sum_{y \in N(x)} f_{A}(y)$. 


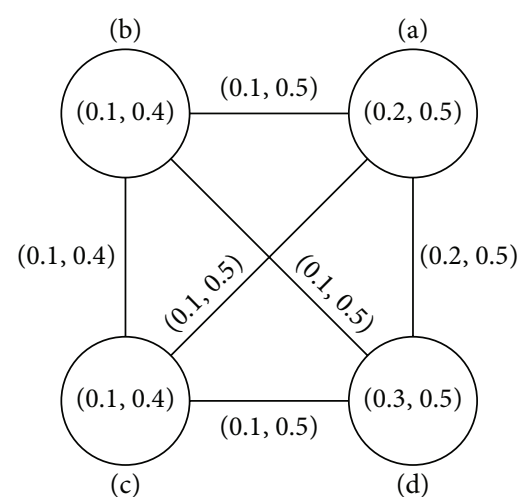

FIGURE 6: $G$ is complete.

Definition 24. Let $G$ be a vague graph. The closed neighbourhood degree of a vertex $x$ is defined by $\operatorname{deg}[x]=$ $\left(\operatorname{deg}_{t}[x], \operatorname{deg}_{f}[x]\right)$, where

$$
\begin{aligned}
\operatorname{deg}_{t}[x] & =\operatorname{deg}_{t}(x)+t_{A}(x), \\
\operatorname{deg}_{f}[x] & =\operatorname{deg}_{f}(x)+f_{A}(x) .
\end{aligned}
$$

If each vertex of $G$ has the same closed neighbourhood degree $m$, then $G$ is called a totally regular vague graph.

Example 25. Consider a graph $G^{*}$ such that $V=\left\{v_{1}, v_{2}, v_{3}\right\}$ and $E=\left\{v_{1} v_{2}, v_{2} v_{3}, v_{3} v_{1}\right\}$. Let $A$ be a vague subset of $V$ and let $B$ be a vague subset of $V$ defined by

$$
\begin{aligned}
& t_{A}\left(v_{1}\right)=0.4, \quad t_{A}\left(v_{2}\right)=0.4, \quad t_{A}\left(v_{3}\right)=0.4, \\
& f_{A}\left(v_{1}\right)=0.1, \quad f_{A}\left(v_{2}\right)=0.1, \quad f_{A}\left(v_{3}\right)=0.1, \\
& t_{B}\left(v_{1} v_{2}\right)=0.3, \quad t_{B}\left(v_{2} v_{3}\right)=0.3, \quad t_{B}\left(v_{3} v_{1}\right)=0.3 \text {, } \\
& f_{B}\left(v_{1} v_{2}\right)=0.6, \quad f_{B}\left(v_{2} v_{3}\right)=0.6, \quad f_{B}\left(v_{3} v_{1}\right)=0.6 \text {. }
\end{aligned}
$$

Routine computations show that a vague graph $G$ is both regular and totally regular.

Definition 26. If there is a vertex which is adjacent to vertices with distinct open neighbourhood degrees, then $G$ is called an irregular vague graph (see Figure 8 ). That is, $\operatorname{deg}(x) \neq m$ for all $x \in V$. If there is a vertex which is adjacent to vertices with distinct closed neighbourhood degrees, then $G$ is called a totally irregular vague graph (see Figure 9).

Example 27. Consider a graph $G^{*}$ such that

$$
V=\left\{v_{1}, v_{2}, v_{3}\right\}, \quad E=\left\{v_{1} v_{2}, v_{2} v_{3}, v_{1} v_{3}\right\} .
$$

Let $A$ be a vague subset of $V$ and let $B$ be a vague subset of $V$ defined by Table 4 .

By routine computations, we have $\operatorname{deg}\left(v_{1}\right)=(0.5,1.1)$, $\operatorname{deg}\left(v_{2}\right)=(0.5,1.0)$, and $\operatorname{deg}\left(v_{3}\right)=(0.4,1.3)$. It is clear that $G$ is an irregular vague graph.
TABLE 4

(a)

\begin{tabular}{cccc}
\hline & $v_{1}$ & $v_{2}$ & $v_{3}$ \\
\hline$t_{A}$ & 0.2 & 0.2 & 0.3 \\
$f_{A}$ & 0.6 & 0.7 & 0.4 \\
\hline
\end{tabular}

(b)

\begin{tabular}{cccc}
\hline & $v_{1} v_{2}$ & $v_{1} v_{3}$ & $v_{2} v_{3}$ \\
\hline$t_{B}$ & 0.1 & 0.1 & 0.2 \\
$f_{B}$ & 0.2 & 0.2 & 0.3 \\
\hline
\end{tabular}

TABLE 5

(a)

\begin{tabular}{ccccc}
\hline & $a$ & $b$ & $c$ & $d$ \\
\hline$t_{A}$ & 0.5 & 0.4 & 0.7 & 0.5 \\
$f_{A}$ & 0.3 & 0.2 & 0.3 & 0.5 \\
\hline
\end{tabular}

(b)

\begin{tabular}{lllll}
\hline & $a b$ & $b c$ & $c d$ & $d a$ \\
\hline$t_{B}$ & 0.2 & 0.4 & 0.2 & 0.4 \\
$f_{B}$ & 0.6 & 0.6 & 0.6 & 0.6 \\
\hline
\end{tabular}

Example 28. Consider a graph $G^{*}$ such that $V=\{a, b, c, d\}$ and $E=\{a b, b c, c d, a d\}$. Let $A$ be a vague subset of $V$ and let $B$ be a vague subset of $V$ defined by Table 5 .

Routine computations show that a vague graph $G$ is both irregular and totally irregular.

Remark 29. In classical (crisp) graph theory, any complete graph $K_{n}$ is regular, but a complete vague graph $G$ is not regular, in general (see Figure 10).

Example 30. Consider a graph $G^{*}$ such that $V=\{x, y, z\}$ and $E=\{x y, y z, z x\}$. Let $A$ be a vague subset of $V$ and let $B$ be a vague subset of $V$ defined by

$$
\begin{array}{lll}
t_{A}(x)=0.5, & t_{A}(y)=0.4, & t_{A}(z)=0.3, \\
f_{A}(x)=0.3, & f_{A}(y)=0.4, & f_{A}(z)=0.5, \\
t_{B}(x y)=0.4, & t_{B}(y z)=0.3, & t_{B}(z x)=0.3, \\
f_{B}(x y)=0.4, & f_{B}(y z)=0.5, & f_{B}(z x)=0.5 .
\end{array}
$$

Clearly, $G$ is a complete vague graph, but $G$ is not regular since $\operatorname{deg}(x) \neq \operatorname{deg}(z)$.

Definition 31 (see [10]). The complement of a vague graph $G=(A, B)$ of $G^{*}=(V, E)$ is a vague graph $\bar{G}=(\bar{A}, \bar{B})$ on $\overline{G^{*}}$, where $\bar{A}=\left(\overline{t_{A}}, \overline{f_{A}}\right)$ and $\bar{B}=\left(\overline{t_{B}}, \overline{f_{B}}\right)$ are defined by

(i)

$$
\bar{V}=V
$$

(ii)

$$
\overline{t_{A}}(x)=t_{A}(x), \quad \overline{f_{A}}(x)=f_{A}(x) \quad \forall x \in V,
$$




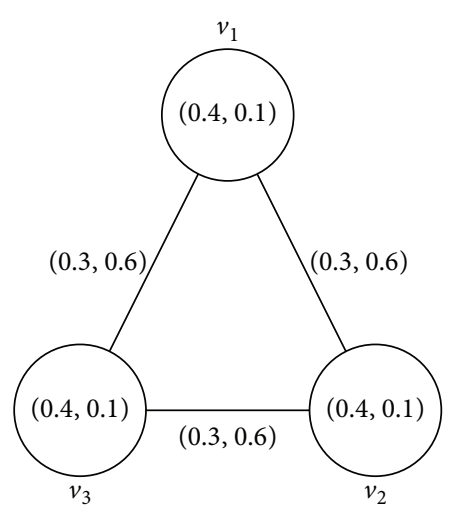

FIgURE 7: $G$ is regular and totally regular.

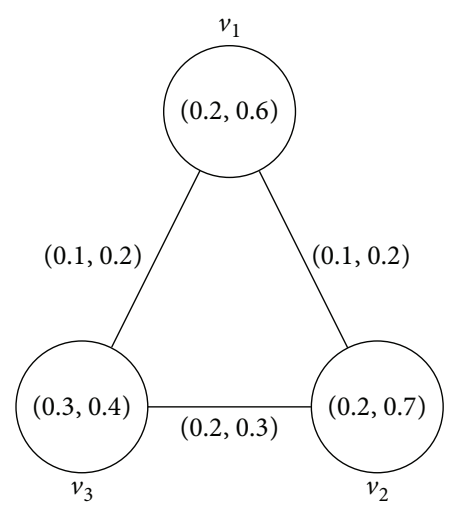

FIGURE 8: $G$ is irregular.

(iii)

$$
\begin{gathered}
\overline{t_{B}}(x y)= \begin{cases}0 & \text { if } t_{B}(x y)>0, \\
\min \left(t_{A}(x), t_{A}(y)\right) & \text { if } t_{B}(x y)=0,\end{cases} \\
\overline{f_{B}}(x y)= \begin{cases}0 & \text { if } f_{B}(x y)>0, \\
\max \left(f_{A}(x), f_{A}(y)\right) & \text { if } f_{B}(x y)=0 .\end{cases}
\end{gathered}
$$

Definition 32. A vague graph $G$ is called self-complementary if $\bar{G} \approx G$.

Example 33. Consider a vague graph $G$.

(1) Clearly, graph $G$ is not isomorphic to its complement $\bar{G}$. Hence $G$ is not self-complementary.

(2) Routine calculations show that $G$ and $\bar{G}$ are irregular and totally irregular, respectively (see Figures 11 and 12).

Example 34. Consider a vague graph $G$.

(1) Clearly, $G$ is isomorphic to its complement $\bar{G}$. Hence $G$ is self-complementary.

(2) Routine calculations show that $G$ and $\bar{G}$ are irregular and totally irregular, respectively.

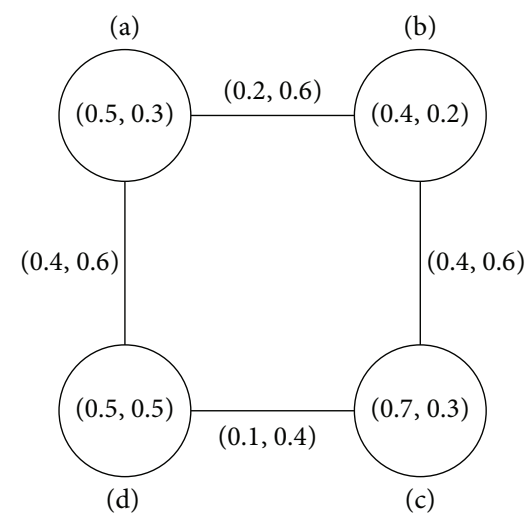

FIGURE 9: $G$ is irregular and totally irregular.

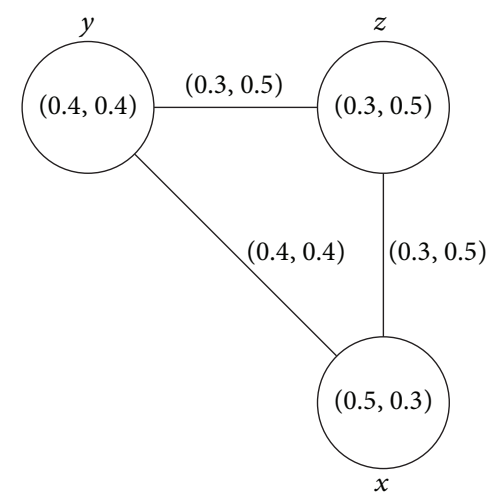

FIGURE 10: $G$ is complete but not regular.

Theorem 35. Let $G=(A, B)$ be a vague graph of a graph $G^{*}$. Then $A=\left(t_{A}, f_{A}\right)$ is a constant function if and only if the following are equivalent:

(a) $G$ is a regular vague graph,

(b) $G$ is a totally regular vague graph.

Proof. Let $A=\left(t_{A}, f_{A}\right)$ be a constant function. To prove that (a) and (b) are equivalent, suppose that $t_{A}(x)=c_{1}$ and $f_{A}(x)=c_{2}$ for all $x \in V$.

(a) $\Rightarrow$ (b): If a vague graph $G$ is $n$-regular, then $\operatorname{deg}_{t}(x)=$ $n_{1}$ and $\operatorname{deg}_{f}(x)=n_{2}$ for all $x \in V$. So

$$
\begin{array}{r}
\operatorname{deg}_{t}[x]=\operatorname{deg}_{t}(x)+t_{A}(x), \\
\operatorname{deg}_{f}[x]=\operatorname{deg}_{f}(x)+f_{A}(x) \\
\forall x \in V .
\end{array}
$$

Thus

$$
\begin{aligned}
& \operatorname{deg}_{t}[x]=n_{1}+c_{1}, \\
& \operatorname{deg}_{f}[x]=n_{2}+c_{2}
\end{aligned}
$$

$$
\forall x \in V \text {. }
$$

Hence, $G$ is totally regular.

(b) $\Rightarrow$ (a): Suppose that $G$ is totally regular. Then for all $x \in V$, we have

$$
k_{1}=\operatorname{deg}_{t}[x]=\operatorname{deg}_{t}(x)+t_{A}(x)=\operatorname{deg}_{t}(x)+c_{1} .
$$




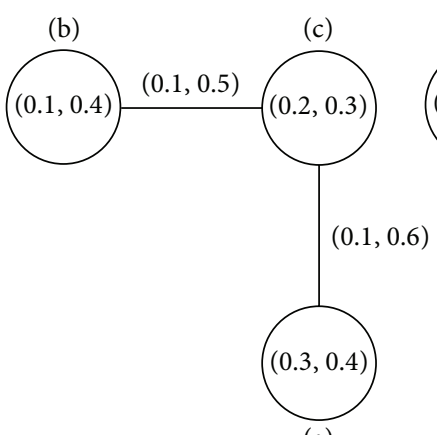

G

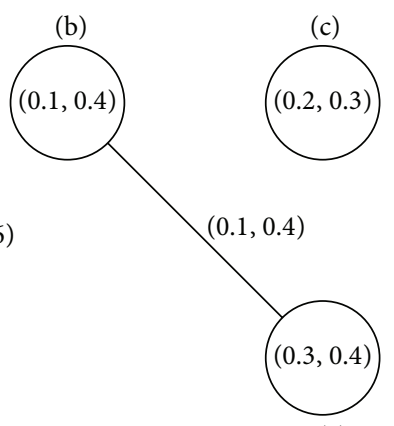

(a)
$\bar{G}$

Figure 11: $G$ and $\bar{G}$ are irregular and totally irregular.

Hence,

$$
\operatorname{deg}_{t}(x)=k_{1}-c_{1} \quad \text { for every } x \in V \text {. }
$$

Similarly we obtain $\operatorname{deg}_{f}(x)=k_{2}-c_{2}$ for every $x \in V$, where $k_{2}=\operatorname{deg}_{f}[x]$. This means that $G$ is regular (see Figure 7).

Hence (a) and (b) are equivalent.

The converse part is obvious.

Example 36. Consider a graph $G^{*}$ such that $V=\left\{v_{1}, v_{2}, v_{3}\right\}$ and $E=\left\{v_{1} v_{2}, v_{1} v_{3}\right\}$. Let $A$ and $B$ be vague subsets defined by

$$
\begin{aligned}
& t_{A}\left(v_{1}\right)=t_{A}\left(v_{2}\right)=t_{A}\left(v_{3}\right)=0.4, \\
& f_{A}\left(v_{1}\right)=f_{A}\left(v_{2}\right)=f_{A}\left(v_{3}\right)=0.1, \\
& t_{B}\left(v_{1} v_{2}\right)=0.2, \quad t_{B}\left(v_{1} v_{3}\right)=0.1, \\
& f_{B}\left(v_{1} v_{2}\right)=0.2, \quad f_{B}\left(v_{1} v_{3}\right)=0.2 .
\end{aligned}
$$

Clearly, $A=\left(t_{A}, f_{A}\right)$ is constant and $G$ is both regular and totally regular.

Finally, we consider examples of vague intersection graph and vague line graph.

Example 37. Consider vague intersection graph which is given in Example 9. Routine calculations show that $P(G)$ is an irregular vague intersection graph, but it is totally regular vague intersection graph.

Example 38. Consider vague line graph which is given in Example 12. Routine calculations show that $L(G)$ is both irregular and totally irregular vague line graph.

\section{Application Example of Vague Digraphs}

Graph models find wide application in many areas of mathematics, computer science, and the natural and social sciences. Often these models need to incorporate more structure than simply the adjacencies between vertices. In studies of group behavior, it is observed that certain people can influence thinking of others. A directed graph, called an influence graph, can be used to model this behavior. Each person of

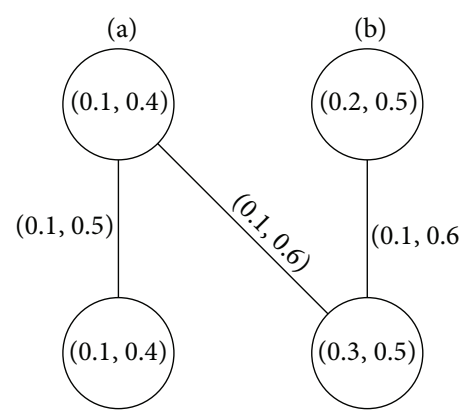

(d) (c)

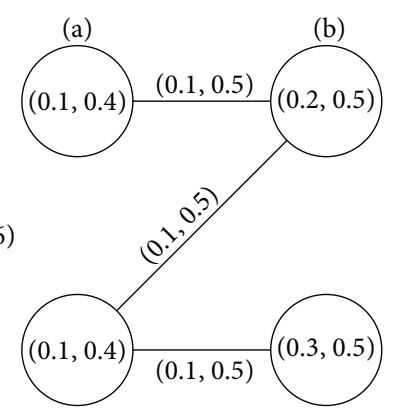

(d) (c)
G

$\bar{G}$

a group is represented by a vertex. There is a directed edge from vertex $x$ to vertex $y$, when the person represented by vertex $x$ influences the person represented by vertex $y$. This graph does not contain loops and it does not contain multiple directed edges.

We now explore vague influence graph model to find out the influential person within a social group. In influence graph, the vertex (node) represents a power (authority) of a person and the edge represents the influence of a person on another person in the social group.

Consider a vague influence graph of a social group. In Figure 13, vague influence graph, the degree of power of a person is defined in terms of its trueness and falseness. The node of the vague influence graph shows the authority a person possesses in the group; for example, Tanzel has $60 \%$ authority in the group, but he does not have $20 \%$ power, and $20 \%$ power is not decided, whereas the edges show the influence of a person on another in a group; for example, Tanzel can influence Amir 30\%, but he cannot convince him $60 \%$, and remaining $10 \%$ is hesitation part.

The degree of a vertex and edge in a vague influence graph is also characterized by an interval $\left[t_{A}(x), 1-f_{A}(x)\right]$. It is worth mentioning here that interval-valued fuzzy sets are not vague sets. In interval-valued fuzzy sets, an interval-valued membership value is assigned to each element of the universe considering the "evidence for $x$ " only, without considering "evidence against $x$." In vague sets both are independently proposed by the decision maker. Thus the vague influence graph can be interpreted in the form of interval-valued membership. The node of the vague influence graph shows the likelihood of power a person possesses in the group; for example, Tanzel posseses $t_{A}=60 \%$ to $1-f_{A}=80 \%$ power, whereas the edges show the interval of influence a person has on another person in a social group. Tanzel has $t_{A}=30 \%$ to $1-f_{A}=40 \%$ influence on Amir and Amir has $t_{A}=40 \%$ to $1-f_{A}=40 \%$ influence on Rajab.

\section{Conclusions}

In 1965, Zadeh introduced the concept of fuzzy sets by extending the range of Eigenfunction of classical sets from $\{0,1\}$ to a closed interval $[0,1]$. However, the membership 


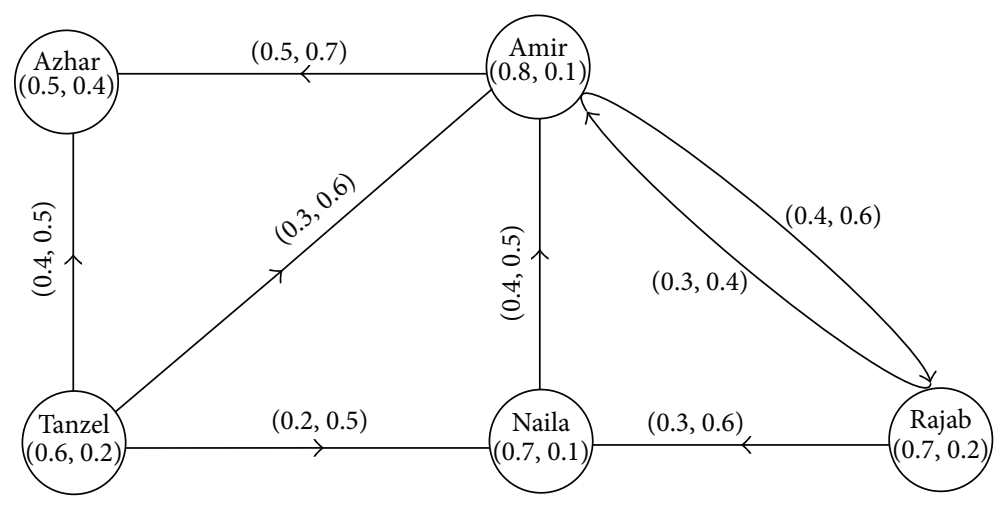

Figure 13: Vague influence graph.

function of a fuzzy set is a single-valued function, which cannot express either the evidence for $x \in X$ or the evidence against $x \in X$. For overcoming the shortcoming, Gau and Buehrer proposed the concept of a vague set in 1993, which is a generalization of the fuzzy set. Essentially, in a fuzzy set each element is associated with a point-value selected from the unit interval $[0,1]$, which is termed the grade of membership in the set. Instead of using point-based membership as in fuzzy sets, interval-based membership is used in a vague set. The interval-based membership in vague sets is more expressive in capturing vagueness of data. We investigate the concepts of vague line and develop the vague influence graph of a social group. The natural extension of this work is exploration of the applications of vague graphs in database theory, expert systems, and neural networks.

\section{Conflict of Interests}

The authors declare that they do not have any conflict of interests regarding the publication of this paper.

\section{References}

[1] R. L. Hemminger and L. W. Beineke, "Line graphs and line digraphs," in Selected Topics in Graph Theory, pp. 271-305, Academic Press, 1978.

[2] L. W. Beineke, "On derived graphs and digraphs," in Beitrge Zur Graphentheorie, H. Sachs, H. Voss, and H. Walther, Eds., pp. 1733, Teubner, Leipzig, Germany, 1968.

[3] W.-L. Gau and D. J. Buehrer, "Vague sets," IEEE Transactions on Systems, Man and Cybernetics, vol. 23, no. 2, pp. 610-614, 1993.

[4] A. Rosenfeld, "Fuzzy graphs," in Fuzzy Sets and Their Applications, L. A. Zadeh, K. S. Fu, and M. Shimura, Eds., pp. 77-95, Academic Press, New York, NY, USA, 1975.

[5] A. Kauffman, Introduction a la Theorie des Sous-Emsembles Flous, vol. 1, Masson et Cie, 1973.

[6] P. Bhattacharya, "Some remarks on fuzzy graphs," Pattern Recognition Letters, vol. 6, no. 5, pp. 297-302, 1987.

[7] J. N. Mordeson, "Fuzzy line graphs," Pattern Recognition Letters, vol. 14 , no. 5, pp. 381-384, 1993.

[8] K. R. Bhutani and A. Battou, "On M-strong fuzzy graphs," Information Sciences, vol. 155, no. 1-2, pp. 103-109, 2003.
[9] M. Akram and W. A. Dudek, "Interval-valued fuzzy graphs," Computers and Mathematics with Applications, vol. 61, no. 2, pp. 289-299, 2011.

[10] N. Ramakrishna, "Vague graphs," International Journal of Computational Cognition, vol. 7, pp. 51-58, 2009.

[11] L. A. Zadeh, "Fuzzy sets," Information and Control, vol. 8, no. 3, pp. 338-353, 1965.

[12] L. A. Zadeh, "Similarity relations and fuzzy orderings," Information Sciences, vol. 3, no. 2, pp. 177-200, 1971.

[13] H.-C. Wu, "Interval-valued optimization problems based on different solution concepts," Pacific Journal of Optimization, vol. 7, no. 1, pp. 173-193, 2011.

[14] X. Yang, T. Y. Lin, J. Yang, Y. Li, and D. Yu, "Combination of interval-valued fuzzy set and soft set," Computers and Mathematics with Applications, vol. 58, no. 3, pp. 521-527, 2009.

[15] M. Akram and K.-P. Shum, "Vague Lie subalgebras over a vague field," Quasigroups and Related Systems, vol. 17, no. 2, pp. 119134, 2009.

[16] R. Biswas, "Vague groups," International Journal of Computational Cognition, vol. 4, no. 2, pp. 20-23, 2006.

[17] I. Bloch, "Geometry of spatial vague sets based on vague numbers and mathematical morphology," in Fuzzy Logic and Applications, vol. 5571 of Lecture Notes in Computer Science, pp. 237-245, 2009.

[18] H. Khan, M. Ahmad, and R. Biswas, "Vague relations," International Journal of Computational Cognition, vol. 5, no. 1, pp. 31-35, 2007. 


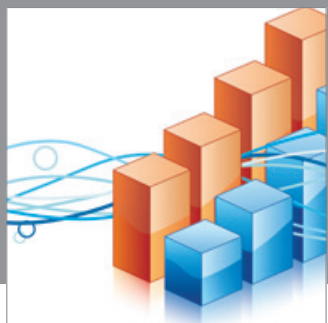

Advances in

Operations Research

mansans

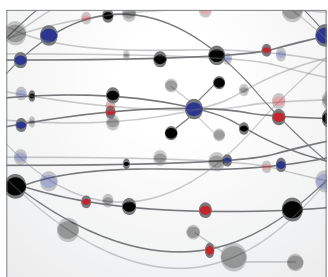

The Scientific World Journal
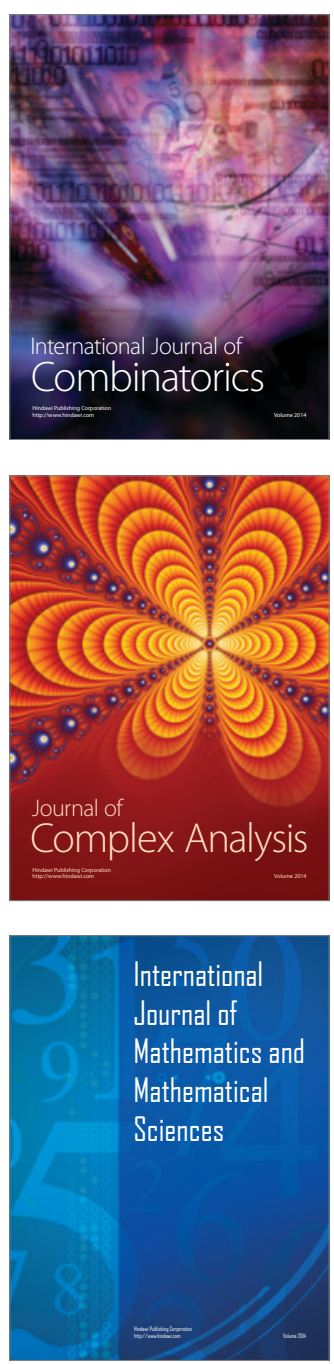
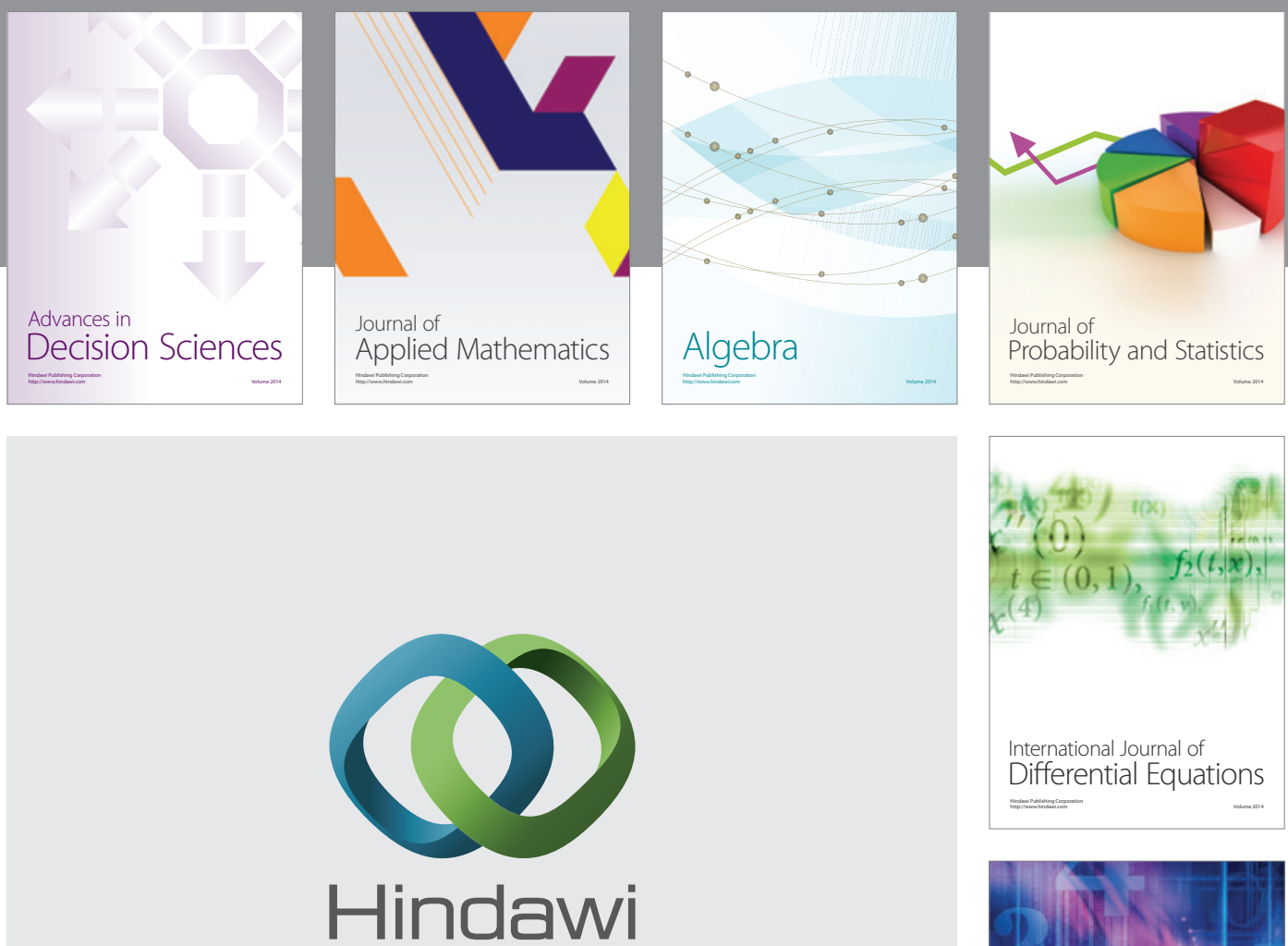

Submit your manuscripts at http://www.hindawi.com
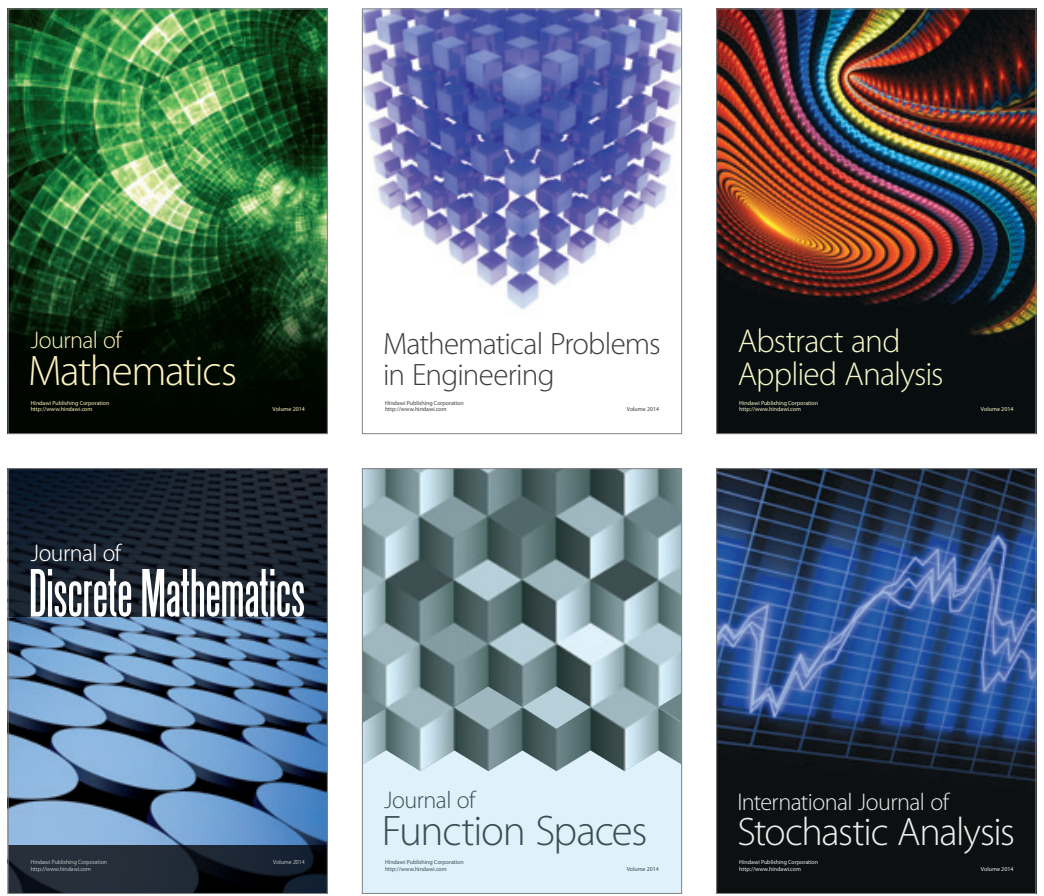

Journal of

Function Spaces

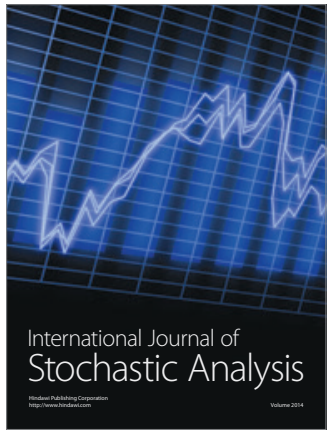

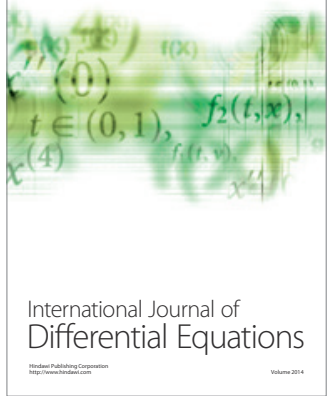
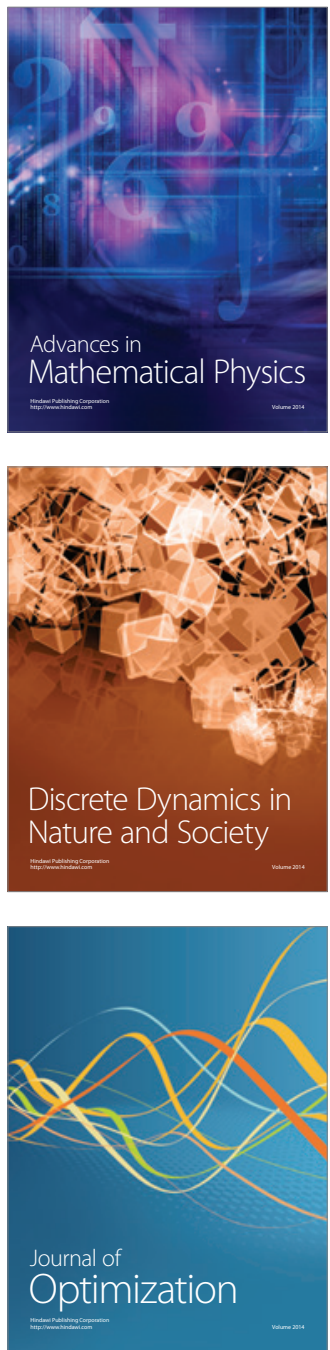